\title{
Modulatory effects of the antioxidant ascorbic acid on the direct genotoxicity of doxorubicin in somatic cells of Drosophila melanogaster
}

\author{
Edson José Fragiorge ${ }^{1}$, Mário Antônio Spanó ${ }^{1}$ and Lusânia Maria Greggi Antunes ${ }^{2}$ \\ ${ }^{1}$ Instituto de Genética e Bioquímica, Universidade Federal de Uberlândia, Uberlândia, MG, Brazil. \\ ${ }^{2}$ Departamento de Análises Clínicas, Toxicológicas e Bromatológicas, Faculdade de Ciências \\ Farmacêuticas de Ribeirão Preto, Universidade de São Paulo, Ribeirão Preto, SP, Brazil.
}

\begin{abstract}
In this study two different crosses involving the wing cell markers mwh and $\mathrm{flr}^{3}$ (standard (ST) cross and high bioactivation (HB) cross, the latter being characterized by a high constitutive level of cytochrome P450 which leads to an increased sensitivity to a number of promutagens and procarcinogens) were used to investigate the modulatory effects of ascorbic acid (AA) combined with the antitumor agent doxorubicin (DXR) in Drosophila melanogaster. We observed that the two different concentrations of AA (50 or $100 \mathrm{mM}$ ) had no effect on spots frequencies, while DXR treatments $(0.2$ or $0.4 \mathrm{mM})$ gave positive results for all types of spots, when compared to negative control. For marker-heterozygous $(\mathrm{MH})$ flies, a protective effect was observed with the lower concentration of $A A(50 \mathrm{mM})$ that was able to statistically decrease the frequency of spots induced by DXR $(0.2 \mathrm{mM})$, while an enhanced frequency of spots induced by DXR was observed with the higher concentration of AA (100 mM), when compared to DXR treatment $(p<0.05)$. These results suggest that AA may interfere with free radicals generated by DXR and with other possible reactive metabolites. The efficiency of AA in protecting the somatic cells of $D$. melanogaster against mutation and recombination induced by DXR is dependent on the dose used and the protection is directly related to the activity of cytochrome P450 enzymes.
\end{abstract}

Key words: ascorbic acid, doxorubicin, Drosophila melanogaster, genotoxicity tests, somatic mutation and recombination test.

Received: June 26, 2006; Accepted: November 23, 2006.

\section{Introduction}

Doxorubicin (DXR), bleomycin, cisplatin and cyclophosphamide are potent drugs used worldwide against many forms of human cancer. The use of these antitumor drugs can cause physiological side-effects and the possible induction of genotoxicity in non-tumor cells (Gentile et al., 1998).

Doxorubicin is an anthracycline antibiotic that is one of the most frequently used active anticancer agents in clinical oncology, especially in the treatment of acute leukemia and lymphomas but also in some solid tumors such as breast, ovarian and endometrial cancers (Minotti et al., 2004). Doxorubicin is also a genotoxic agent that inhibits the activity of the enzyme topoisomerase II, resulting in the accumulation of DNA strand breaks that, if not repaired by the cell, can provoke mutations and chromosomal aberrations in tumor and non-tumor cells in mammalian systems (Islaih et al., 2005; Resende et al., 2006).

Send correspondence to Mário Antônio Spanó. Laboratório de Mutagênese, Instituto de Genética e Bioquímica, Universidade Federal de Uberlândia, Bloco D - Sala 2D52, Campus Umuarama, 38400-902 Uberlândia, MG, Brazil. E-mail: maspano@ufu.br.
Cellular enzymes are capable of converting DXR into free-radical metabolites (Benchekroun et al., 1992; Menegola et al., 2001). Furthermore, a significant reduction in total plasma antioxidant capacity was observed in smallcell lung cancer patients treated with DXR (Erhola et al., 1996). It is important to reduce the genotoxicity of DXR in non-tumor cells, a goal that has been achieved experimentally by concurrent administration of free radical scavengers such as antioxidants (Amara-Mokrane et al., 1996; Antunes and Takahashi, 1998; Gentile et al., 1998; Costa and Nepomuceno, 2006; Antunes et al., 2007).

Ascorbic acid (AA) is involved in various biological processes, including free radical scavenging, and it has been demonstrated that treatment with AA significantly reduced the genotoxicity of well-known mutagens (Odin, 1997; Cabrera, 2000; Nefic, 2001; Rao et al., 2001; Kaya et al., 2002; Siddique et al., 2005). However, administration of large amounts of AA to biological systems has lead to genotoxic effects in several different test systems (Shamberger, 1984) because AA has both antioxidant and prooxidant activities (Bijur et al., 1997). 
The fruit fly Drosophila melanogaster with its well development array of genotoxicity test systems has been used in a number of studies on the modulatory effects of various compounds, along with somatic mutation and recombination tests (SMART) have been employed (Graf et al., 1998; Kaya et al., 2002; Rizki et al., 2004; Sinigaglia et al., 2004; Romero-Jiménez et al., 2005; Costa and Nepomuceno, 2006).

In the study described in the present paper two different crosses involving the wing cell markers $m w h$ and $f l r^{3}$ were used to investigate the modulatory effects of AA combined with the antitumor agent DXR in Drosophila: the standard (ST) cross and the high bioactivation (HB) cross, the latter being characterized by a high constitutive level of cytochrome P450 which leads to an increased sensitivity to a number of promutagens and procarcinogens.

\section{Materials and Methods}

\section{Chemicals}

Doxorubicin (DXR) $\left(\right.$ Doxina $^{\circledR}$ - Eurofarma Laboratórios Ltda., São Paulo, Brazil - CAS n. 23214-92-8) was obtained from the Hospital de Clínicas da Universidade Federal de Uberlândia - MG, Brazil. Ascorbic acid (AA) (CAS n. 50-81-7) was purchased from Fluka (Buchs, Switzerland). The solutions were always freshly prepared in distilled water immediately before use.

\section{Drosophila stocks and crosses}

The markers multiple wing hairs ( $m w h, 3-0.3)$ and flare $\left(f l r^{3}, 3-38.8\right)$ used in the wing spot test are at the tip and roughly in the middle of the left arm of chromosome 3 , respectively. Two crosses were carried out to produce the experimental larval progeny: 1] Standard (ST) cross,

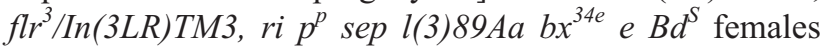
crossed with $m w h$ males; 2] High bioactivation (HB) cross, ORR; ll $^{3} / \operatorname{In}(3 L R) T M 3$, ri $p^{p}$ sep l(3)89Aa bx ${ }^{34 e}$ e $B d^{S}$ females crossed with $m w h$ males (Graf et al., 1984, 1989; Graf and van Schaik, 1992).

\section{Somatic mutation and recombination test}

From the two crosses eggs were collected for $8 \mathrm{~h}$ in culture bottles with an agar-agar base $(4 \% \mathrm{w} / \mathrm{v})$ topped with a thick layer of fermenting live baker's yeast supplemented with sucrose. The larvae were washed out of the bottles $72 \pm 4 \mathrm{~h}$ later with tap water and collected in a stainless steel strainer. For chronic feeding, a series of vials were prepared with $1.5 \mathrm{~g}$ mashed potato flakes (Yoki Alimentos S.A., Brazil) and $5 \mathrm{~mL}$ of different concentrations of AA (50 or $100 \mathrm{mM})$ alone and AA (50 or $100 \mathrm{mM})$ in association with DXR (0.2 or $0.4 \mathrm{mM})$. Negative (distilled water) and positive (DXR 0.2 or $0.4 \mathrm{mM}$ ) controls were included in both experiments. Equal batches of $72 \mathrm{~h}$ larvae were then distributed into the vials where they fed for the remainder of their larval life $(\sim 48 \mathrm{~h})$ pupated and hatched as adult flies. Each treatment was done in duplicate.

Each cross produce two types of progeny, i.e. marker-heterozygous (MH) ( $\left.m w h \mathrm{flr}^{+} / \mathrm{mwh}^{+} \mathrm{flr}^{3}\right)$ and balancer-heterozygous (BH) $\left(m w h f l r^{+} / m w h^{+} T M 3, B d^{S}\right)$ flies. The dominant $B d^{S}$ marker allows the wings of these two genotypes to be distinguished. The hatched flies were stored in $70 \%(\mathrm{v} / \mathrm{v})$ ethanol and the wings mounted on slides with Faure's solution and analyzed under a compound microscope at 400x magnification (Graf et al., 1984). Frequency and size of single and twin spots were recorded.

\section{Statistical analysis}

The data were evaluated according to the multipledecision procedure of Frei and Würgler (1988; 1995). The frequencies of each type of mutant clones per fly were compared with the concurrent negative control series using the conditional binomial test of Kastenbaum and Bowman (1970), with significance levels set at $\alpha=\beta=0.05$. For the analysis of the modulatory effects of AA on DXR-induced genotoxicity, the data were evaluated according to the Mann-Whitney nonparametric U-test and Wilcoxon rank sum text (Frei and Würgler, 1995).

\section{Results}

All compounds were tested in two different experiments. The data, based on scoring 40 wings, were pooled after verifying that the two independent experiments were in agreement with good reproducibility. In this wing cell assay, the following types of spots were evaluated separately: small single spots with only one or two affected cells, large single spots with more than two affected cells, twin spots and total of spots observed for both $\mathrm{MH}$ and $\mathrm{BH}$ flies. For the statistical evaluation the results were compared with the corresponding control.

\section{Standard (ST) cross}

Table 1 shows the results obtained in the wing spot test for $\mathrm{MH}$ and $\mathrm{BH}$ individuals of the ST-cross. Two different concentrations of AA (50 or $100 \mathrm{mM}$ ) were tested and both were negative $(p>0.05)$. The DXR $(0.2$ or $0.4 \mathrm{mM}$ ) treatments gave positive results for all types of spots on the wings when compared to negative control $(\mathrm{p}<0.05)$. The twin spots indicate a recombinagenic activity of DXR. Combined co-treatment with AA (50 mM) and DXR $(0.2 \mathrm{mM})$ presented a reduction statistically significant in the twin and total of spots (43\% total) observed when compared with DXR alone $(\mathrm{p}<0.05)$. The other treatments (AA $100 \mathrm{mM}$ plus DXR $0.2 \mathrm{mM}$ and AA $50 \mathrm{mM}$ plus DXR $0.4 \mathrm{mM}$ ) did not alter the genotoxicity of DXR on the wing spot test. DXR $(0.4 \mathrm{mM})$ tested in combination with the higher concentration of AA shows a positive increase in the frequencies of twin spots and total of spots ( $42 \%$ total). 
Table 1 - Summary of results obtained with the Drosophila somatic mutation and recombination test (SMART) in the marker-heterozygous (MH) and balancer-heterozygous (BH) progeny of the standard (ST) cross after chronic treatment of larvae with ascorbic acid (AA) and doxorubicin (DXR).

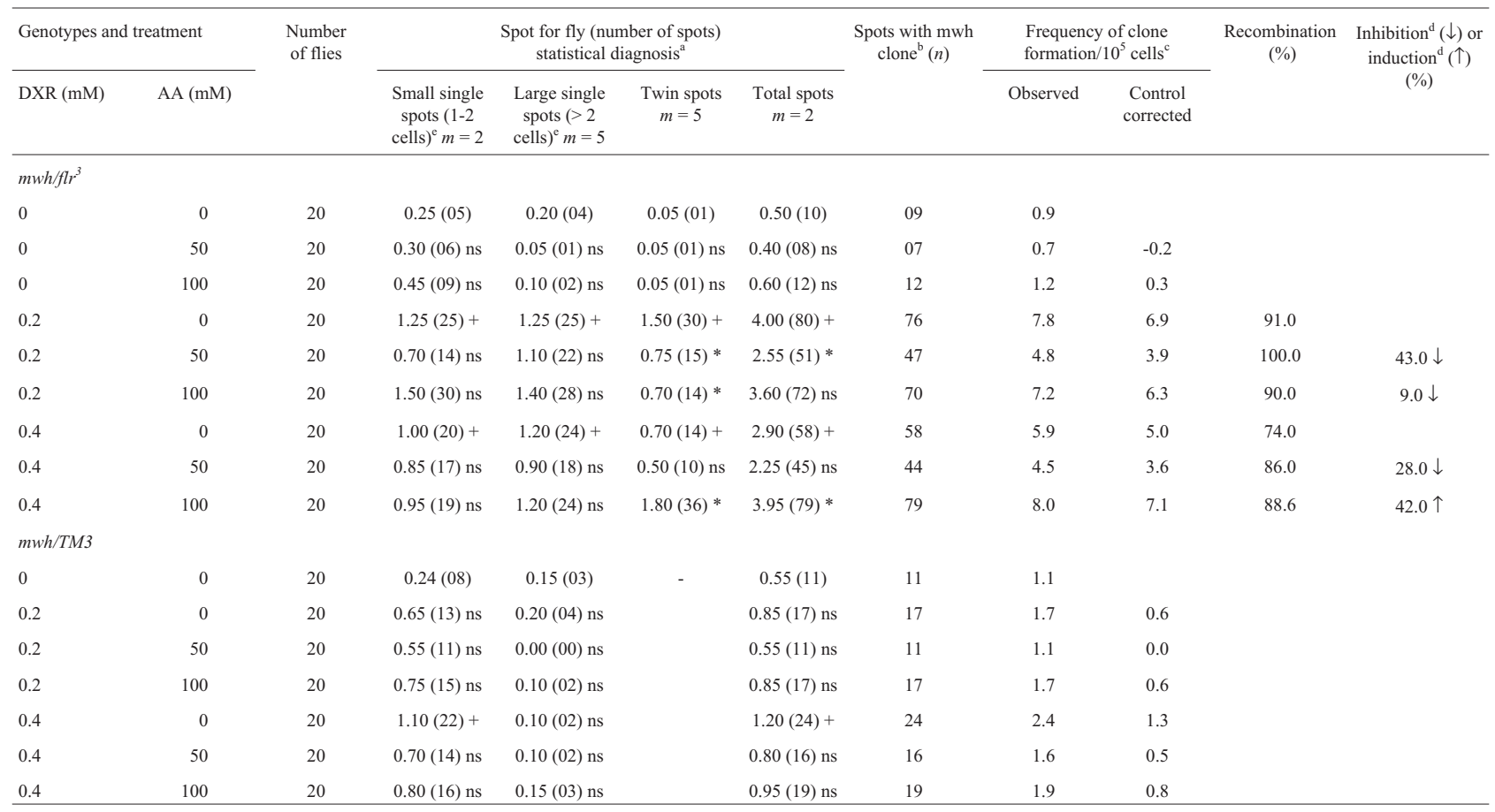

Marker-trans-heterozygous flies $\left(m w h / f l r^{3}\right)$ and balancer-heterozygous flies $(m w h / T M 3)$ were evaluated.

${ }^{a}$ Statistical diagnoses according to Frei and Würgler [1995]. U-test, two-sided, probability levels:,$+ \mathrm{p}<0.05$ vs. untreated control; *, p $<0.05$ vs. DXR only; ns, not significant.

${ }^{\mathrm{b}}$ Considering $m w h$ clones from $m w h$ single and twin spots.

${ }^{c}$ Frequency of clone formation: clones/flies/48,800 cells (without size correction).

${ }^{\mathrm{d}}$ Calculated as [DXR alone - DXR + AA) / DXR alone] X 100, according to Abraham (1994).

${ }^{\mathrm{e}}$ Including rare $f l r^{3}$ single spots.

For BH individuals neither AA nor DXR (with exception of DXR $0.4 \mathrm{mM}$ ) induced significant increase in the spot frequencies when compared to negative control $(p>0.05)$. The combined co-treatment with AA and DXR was ineffective in the inhibition of small single spots, large simple spots and total spots when compared to DXR alone $(\mathrm{p}>0.05)$.

Comparison of the frequencies of wing spots in the $\mathrm{BH}$ and $\mathrm{MH}$ descendents indicated that recombination was a major response, indicating, under these experimental conditions, genotoxic (from 74 untill $100 \%$ recombinagenic) activity.

\section{High bioactivation (HB) cross}

The number of spots and their distribution obtained for $\mathrm{MH}$ and $\mathrm{BH}$ individuals of the $\mathrm{HB}$-cross are presented in Table 2. Both concentrations of AA were not genotoxic but DXR showed genotoxic activity by increasing the frequencies of all types of spots $(\mathrm{p}<0.05)$. The co-treatments with the lower concentrations of AA and DXR produced a statistically significant reduction $(63 \%)$ in the frequencies of small single spots, large single spots and total of spots $(\mathrm{p}<0.05)$, while co-treatments with DXR $(0.2 \mathrm{mM})$ and AA $(100 \mathrm{mM})$ led to a statistically significant reduction only in the frequencies of twin spots. The same was not observed in the other treatment with AA and DXR, and the series treated with AA $100 \mathrm{mM}$ and DXR $0.4 \mathrm{mM}$ showed a positive increase $(70 \%)$ in the total of spots when compared to DXR alone.

For BH flies no positive effect were observed for AA or DXR, alone or in combination, when compared to negative control $(\mathrm{p}>0.05)$. However, AA $50 \mathrm{mM}$ did alter the DXR $0.4 \mathrm{mM}$ genotoxicity, increasing the frequencies of total spots when compared to DXR $0.4 \mathrm{mM}(\mathrm{p}<0.05)$.

Comparison of the frequencies of wing spots in the $\mathrm{BH}$ and $\mathrm{MH}$ descendants indicated that, for the $\mathrm{HB}$ cross, the recombinagenic activity ranged from 37 to $98 \%$.

\section{Discussion}

In this investigation, we used the wing somatic mutation and recombination test in $D$. melanogaster because it represents a rapid and inexpensive way to evaluate the genotoxicity/antigenotoxicity of single compounds as well as of complex mixtures (Graf et al., 1996). It has been demonstrated by the wing spot test that the co-administration of coffee is effective in significantly reducing the frequencies of single and twin spots induced by cyclophosphamide, 
Table 2 - Summary of results obtained with the Drosophila somatic mutation and recombination test (SMART) in the marker-heterozygous (MH) and balancer-heterozygous $(\mathrm{BH})$ progeny of the high bioactivation (HB) cross after chronic treatment of larvae with ascorbic acid (AA) and doxorubicin (DXR)

\begin{tabular}{|c|c|c|c|c|c|c|c|c|c|c|c|}
\hline \multicolumn{2}{|c|}{ Genotypes and treatment } & \multirow[t]{2}{*}{$\begin{array}{l}\text { Number } \\
\text { of flies }\end{array}$} & \multicolumn{4}{|c|}{$\begin{array}{l}\text { Spot for fly (number of spots) } \\
\text { statistical diagnosis }^{\mathrm{a}}\end{array}$} & \multirow[t]{2}{*}{$\begin{array}{c}\text { Spots with } \\
\text { mwh clone }{ }^{\mathrm{b}}(n)\end{array}$} & \multicolumn{2}{|c|}{$\begin{array}{l}\text { Frequency of clone } \\
\text { formation } / 10^{5} \text { cells }^{\mathrm{c}}\end{array}$} & \multirow[t]{2}{*}{$\begin{array}{c}\text { Recombination } \\
(\%)\end{array}$} & \multirow{2}{*}{$\begin{array}{c}\text { Inhibition }^{\mathrm{d}}(\downarrow) \\
\text { or induction }^{\mathrm{d}}(\uparrow) \\
(\%)\end{array}$} \\
\hline DXR (mM) & $\mathrm{AA}(\mathrm{mM})$ & & 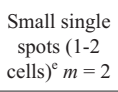 & $\begin{array}{c}\text { Large single } \\
\text { spots }(>2 \\
\text { cells) }{ }^{\mathrm{e}} m=5\end{array}$ & $\begin{array}{c}\text { Twin spots } \\
m=5\end{array}$ & $\begin{array}{c}\text { Total spots } \\
m=2\end{array}$ & & Observed & $\begin{array}{l}\text { Control } \\
\text { corrected }\end{array}$ & & \\
\hline \multicolumn{12}{|l|}{$m w h / f l r^{3}$} \\
\hline 0 & 0 & 20 & $0.95(19)$ & $0.05(01)$ & $0.05(01)$ & $1.05(21)$ & 21 & 2.04 & & & \\
\hline 0 & 50 & 20 & $1.25(25) \mathrm{ns}$ & $0.05(01) \mathrm{ns}$ & $0.00(00) \mathrm{ns}$ & $1.30(26) \mathrm{ns}$ & 25 & 2.56 & 0.52 & & \\
\hline 0 & 100 & 20 & $0.40(08) \mathrm{ns}$ & $0.20(04) \mathrm{ns}$ & $0.05(01) \mathrm{ns}$ & $0.65(13) \mathrm{ns}$ & 13 & 1.33 & -0.71 & & \\
\hline 0.2 & 0 & 20 & $2.25(45)+$ & $1.25(25)+$ & $0.70(14)+$ & $4.20(84)+$ & 83 & 8.5 & 6.46 & 92.0 & \\
\hline 0.2 & 50 & 20 & $1.00(20)^{*}$ & $0.60(12) *$ & $0.55(11) \mathrm{ns}$ & $2.15(43) *$ & 43 & 4.4 & 2.36 & 49.0 & $63.0 \downarrow$ \\
\hline 0.2 & 100 & 20 & $2.15(43) \mathrm{ns}$ & $1.10(22) \mathrm{ns}$ & $1.30(26) *$ & $4.55(91) \mathrm{ns}$ & 87 & 8.91 & 6.87 & 98.0 & $6.0 \uparrow$ \\
\hline 0.4 & 0 & 20 & $1.25(25) \mathrm{ns}$ & $0.80(16)+$ & $0.65(13)+$ & $2.70(54)+$ & 54 & 5.53 & 3.49 & 94.0 & \\
\hline 0.4 & 50 & 20 & $1.35(27) \mathrm{ns}$ & $0.75(15) \mathrm{ns}$ & $0.30(06) \mathrm{ns}$ & $2.40(48) \mathrm{ns}$ & 47 & 4.81 & 2.77 & 37.0 & $21.0 \downarrow$ \\
\hline \multicolumn{12}{|l|}{$m w h / T M 3$} \\
\hline 0 & 0 & 20 & $1.00(20)$ & $0.10(02)$ & - & $1.10(22)$ & 22 & 2.25 & & & \\
\hline 0.2 & 0 & 20 & $1.30(26) \mathrm{ns}$ & $0.05(01) \mathrm{ns}$ & & $1.35(27) \mathrm{ns}$ & 27 & 2.76 & 0.51 & & \\
\hline 0.2 & 50 & 20 & $1.00(20) \mathrm{ns}$ & $0.10(02) \mathrm{ns}$ & & $1.10(22) \mathrm{ns}$ & 22 & 2.25 & 0.00 & & \\
\hline 0.2 & 100 & 20 & $1.05(21) \mathrm{ns}$ & $0.10(02) \mathrm{ns}$ & & $1.15(23) \mathrm{ns}$ & 23 & 2.35 & 0.10 & & \\
\hline 0.4 & 0 & 20 & $1.15(23) \mathrm{ns}$ & $0.05(01) \mathrm{ns}$ & & $1.20(24) \mathrm{ns}$ & 24 & 2.45 & 0.20 & & \\
\hline 0.4 & 50 & 20 & $1.70(34) \mathrm{ns}$ & $0.25(05) \mathrm{ns}$ & & $1.95(39) *$ & 39 & 3.99 & 1.74 & & \\
\hline 0.4 & 100 & 20 & $1.05(21) \mathrm{ns}$ & $0.10(02) \mathrm{ns}$ & & $1.15(23) \mathrm{ns}$ & 23 & 2.35 & 0.10 & & \\
\hline
\end{tabular}

Marker-trans-heterozygous flies $\left(m w h / f l r^{3}\right)$ and balancer-heterozygous flies $(m w h / T M 3)$ were evaluated.

${ }^{a}$ Statistical diagnoses according to Frei and Würgler [1995]. U-test, two-sided, probability levels:,$+ \mathrm{p}<0.05$ vs. untreated control; $*, \mathrm{p}<0.05$ vs. DXR only; ns, not significant.

${ }^{\mathrm{b}}$ Considering $m w h$ clones from $m w h$ single and twin spots.

${ }^{c}$ Frequency of clone formation: clones/flies/48,800 cells (without size correction).

${ }^{\mathrm{d}}$ Calculated as [DXR alone - DXR + AA) / DXR alone] X 100, according to Abraham (1994).

${ }^{\mathrm{e}}$ Including rare $f l r^{3}$ single spots.

diethylnitrosamine, mitomicyn $\mathrm{C}$, procarbazine and urethane (Abraham, 1994) and that turmeric inhibited the genotoxic effect of urethane (El Hanss et al., 1999). Furthermore, sodium selenite has been shown to be antigenotoxic in combination with potassium dichromate (Rizki et al., 2001) and AA modulated the genotoxic action of several mutagens (Kaya et al., 2002), showing the suitability of this test system for mimicking the normal intake of substances.

Doxorubicin (DXR) was selected in this study because it is an effective clastogenic and potent carcinogenic agent, and DXR has genotoxic effects that do not require enzymatic activation (Dhawan et al., 2003). The successful use of this antitumor agent is restricted by the risk of developing cardiotoxicity. This risk increases exponentially with cumulative dose, and studies have reported that $10 \%$ to $26 \%$ of patients administered cumulative anthracycline doses above those recommended develop congestive heart failure, and that more than $50 \%$ of patients administered these doses will experience measurable functional impairment months to years after the end of therapy (Jensen, 2006). Possible clinical options for reducing DXR-induced cardiotoxicity include agents such as antioxidants that pre- vent oxygen-free radical generation. The patterns of DNA damage in anthracycline-treated cancer cells seem to support the concept that direct oxidative lesions only occur if cancer cells are exposed to elevated concentrations of anthracyclines. Clinically relevant concentrations have been shown to cause the formation of protein-associated DNA single-strand and double-strand breaks, which might result from anthracycline inhibition of topoisomerase II by forming an anthracycline-DNA topoisomerase II complex (Gewirtz, 1999; Minotti et al., 2004).

The genotoxicity of DXR has been discussed for many years. In Drosophila assay systems, DXR induced sex-liked recessive lethals (Clements et al., 1984) and was classified as a strong mutagen inducing all types of spots (Frei et al., 1985). The spots can be due to different genotoxic events, either mitotic recombination or mutations such as deletion, point mutation, specific types of translocations, etc. The significant induction of twin spots indicates that DXR, a strong direct-acting mutagen, is capable of inducing mitotic recombination. According to Lehmann et al. (2003) DXR is a preferential inducer of homologous recombination when compared with mutational events in D. melanogaster somatic cells. In our present study, DXR 
treatment gave positive results for all types of spots, although the DXR concentrations used in our investigation were lower than those used by Frei et al. (1985) and, according to Lehmann et al. (2003), DXR preferentially induced recombination rather than other genotoxic events. The data presented in our paper do not show a doseresponse effect of DXR. The frequencies of spots at the highest concentration of DXR $(0.4 \mathrm{mM})$ were no higher than those observed at the lower one $(0.2 \mathrm{mM})$. The same pattern was found by Spanó et al. (2001) for different concentrations of 9,10-dimethylantracene on the wing spot test in Drosophila. The protection afforded by antioxidants against DXR genotoxicity appears not to depend on the treatment schedule, since there was no modification in protection for time intervals of 30 or $60 \mathrm{~min}$ in the antioxidant pretreatment and administration of DXR in rats (Prahalathan et al., 2006).

We found that after treatments with DXR it was clear that the frequencies of wing spots on $\mathrm{BH}$ flies were lower than those found on $\mathrm{MH}$ flies. Nevertheless, in the BH flies the small single spots induced by DXR $(0.4 \mathrm{mM})$ in the ST-cross were statistically significant compared with those of the respective negative control. The large majority of the spots induced by DXR on the wings of MH flies are ascribable to mitotic recombination, but a small number of them have other causes and may be due to point mutation or chromosome breaks.

The results of DXR photodegradation in plasma, urine and cell culture medium as measured by HPLC indicates that DXR is very unstable in cell culture medium when exposed to light (Le Bot et al., 1988). Therefore, it is important for the correct interpretation of the effects of DXR activity on biological systems, especially when culture medium is used, to investigate DXR genotoxicity in the absence of light, as performed in the present study.

Ascorbic acid (AA) is known to have both antimutagenic and anticarcinogenic activities. According to Halliwell (2001) AA, a water-soluble glucose derivative, has considerable antioxidant activity in vitro, in part because of its ease of oxidation and because the semidehydroascorbate radical derived from it is of low reactivity, but there are conflicting effects of AA reported on the induction of DNA strand breaks, micronuclei and frequency of chromosomal aberrations. It has been previously reported that AA successfully inhibited the chromosome aberrations induced by DXR in rat bone marrow cells (Antunes and Takahashi, 1998), micronuclei in cytokinesis-blocked human lymphocytes and the chromosomal aberration assay in V79 Chinese hamster cells induced by the mycotoxin patulin (Alves et al., 2000) and mercury-induced genotoxicity in human blood cultures (Rao et al., 2001). However, administration of high doses of AA appears to have mutagenic effects in different test systems. In human blood lymphocytes culture treated with lower concentrations of AA there was a significant reduction in chromosomal aber- rations induced by DXR but at higher doses AA did not present the same protective effect and was cytotoxic (Antunes and Takahashi, 1999).

We observed that the two different concentrations of AA tested (50 and $100 \mathrm{mM}$ ) had no effect on spots frequencies. Tripathy et al. (1990) observed that larvae exposed to 100 and $300 \mathrm{mM}$ showed inconclusive results for the induction of the small single spots and negative results for large single spots. Kaya et al. (2002) showed that AA (25, 75 and $250 \mathrm{mM}$ ) did not induce significant increases in the frequency of mutant clones in the Drosophila wing spot test. The authors concluded that the differences between the control and the AA-treated series were not of biological significance and AA was considered negative.

The ability of AA to modulate the genotoxic action of several mutagens has also been investigated in the wing spot test of D. melanogaster. Nevertheless, when co-treatment experiments with AA were carried out, different results were found (Kaya et al., 2002). In our present study, combined co-treatment with the lower concentration of AA plus DXR led to a statistically significant reduction in the frequencies of twin and total of spots in $\mathrm{MH}$ flies in the ST-cross and in the frequencies of small single spots, large single spots and total spots in the HB-cross, while treatments with DXR $(0.4 \mathrm{mM}$ plus $100 \mathrm{mM}$ AA in both crosses) increased the frequencies of total spots when compared to DXR alone.

Similar results were obtained by Cederberg and Ramel (1989) who reported that AA co-treatment had a modifying effect in the wing spot test on genotoxicity induced by the antitumor agent bleomycin. Graf et al. (1998) reported that $\mathrm{AA}$ and catechin were able to protect against in vivo nitrosation products of methyl urea in combination with sodium nitrite, while Kaya et al. (2002) found that AA was effective in reducing the genotoxicity of $\mathrm{K}_{2} \mathrm{Cr}_{2} \mathrm{O}_{7}$ virtually to the control level in the Drosophila wing spot test. On the contrary, co-treatment experiments by Kaya et al., (2002) indicate that different concentrations of AA (25, 75 and $250 \mathrm{mM}$ ) did not show any antigenotoxic effect on the genotoxicity of 4-nitroquinoline 1-oxide (4-NQO) and Kaya et al. (2002) found that when co-treatments experiments with cobalt chloride $\left(\mathrm{CoCl}_{2}\right)$ were carried out, instead of reducing the genotoxicity of $\mathrm{CoCl}_{2} \mathrm{AA}$ acts as a co-mutagen by inducing a significant increase in the frequency of mutant clones over the values obtained with $\mathrm{CoCl}_{2}$ alone.

Bijur et al. (1997) showed that in Chinese hamster ovary cell line AS52 there is a temporal relationship between the anti- and prooxidant activities of a physiologically relevant concentration of AA and oxidative stress. Treatment of cells with AA prior to treatment of the cells with a radical generating system (RGS) results in a statistically significant inhibition of the cytotoxicity and mutagenicity. Conversely co-treatment of cells with AA and RGS results in a statistically significant increase in both the 
cytotoxic and mutagenic effects of oxidative stress. Konopacka et al. (1998) demonstrated the modifying effect of treatment with AA on the clastogenic activity of gamma rays in mice as measured by the micronucleus assay in bone marrow polychromatic erythrocytes and exfoliated bladder cells. Depending on AA concentration, the number of micronucleated polychromatic erythrocytes can be enhanced or reduced.

In conclusion, under the present experimental conditions, our data shows that DXR induced mitotic recombination in somatic cells of Drosophila and that $50 \mathrm{mM}$ of AA protected against DXR genotoxicity while $100 \mathrm{mM}$ of AA enhanced the frequencies of DXR-induced spots. These results suggest that AA may interfere with free radicals generated by DXR and with other possible reactive metabolites which elevate spot frequencies in D. melanogaster.

\section{References}

Abraham SK (1994) Antigenotoxicity of coffee in the Drosophila assay for somatic mutation and recombination. Mutagenesis 9:383-386.

Alves I, Oliveira NG, Laires A, Rodrigues AS and Rueff J (2000) Induction of micronuclei and chromosomal aberrations by the mycotoxin patulin in mammalian cells: Role of ascorbic acid as a modulator of patulin clastogenicity. Mutagenesis 15:229-234.

Amara-Mokrane YA, Lehucher-Michel MP, Balansard G, Duménil G and Botta A (1996) Protective effects of $\alpha$-hederin, chlorophyllin and ascorbic acid towards the induction of micronuclei by doxorubicin in cultured human lymphocytes. Mutagenesis 11:161-167.

Antunes LMG, Bueno RBL, Dias FL and Bianchi MLP (2007) Acetylsalicylic acid exhibits anticlastogenic effects on cultured human lymphocytes exposed to doxorubicin. Mutat Res 626:155-161.

Antunes LMG and Takahashi CS (1998) Effects of high doses of vitamins $\mathrm{C}$ and $\mathrm{E}$ against doxorubicin-induced chromosomal damage in Wistar rat bone marrow cells. Mutat Res 419:137-143.

Antunes LMG and Takahashi CS (1999) Protection and induction of chromosomal damage by vitamin $\mathrm{C}$ in human lymphocyte cultures. Teratog Carcinog Mutagen 19:53-59.

Benchekroun MN, Sinha BK and Robert J (1992) Doxorubicininduced oxygen free radical formation in sensitive and doxorubicin-resistant variants of rat glioblastoma cell lines. FEBS Letters 322:295-298.

Bijur GN, Ariza ME, Hitchcock CL and Williams MV (1997) Antimutagenic and promutagenic activity of ascorbic acid during oxidative stress. Environ Mol Mutagen 30:339-345.

Cabrera G (2000) Effect of five dietary antimutagens on the genotoxicity of six mutagens in the microscreen prophageinduction assay. Environ Mol Mutagen 36:206-220.

Cederberg H and Ramel C (1989) Modifications of the effect of bleomycin in the somatic mutation and recombination test in Drosophila melanogaster. Mutat Res 214:69-80.

Clements J, Phillips M and Todd N (1984) Mutagenicity of adriamycin in Drosophila melanogaster. Mutat Res 135:175-179.
Costa WF and Nepomuceno JC (2006) Protective effects of a mixture of antioxidant vitamins and minerals on the genotoxicity of doxorubicin in somatic cells of Drosophila melanogaster. Environ Mol Mutagen 47:18-24.

Dhawan A, Kayani MA, Parry JM, Parry E and Anderson D (2003) Aneugenic and clastogenic effects of doxorubicin in human lymphocytes. Mutagenesis 18:487-490.

El Hamss R, Analla M, Campos-Sánchez J, Alonso-Moraga A, Muñoz-Serrano A and Idaomar M (1999) A dose dependent anti-genotoxic effect of turmeric. Mutat Res 446:135-139.

Erhola M, Kellokumpu-Lehtinen P, Metsä-Ketelä T, Alanko K and Nieminen MM (1996) Effects of anthracyclin-based chemotherapy on total plasma antioxidant capacity in small cell lung cancer patients. Free Radic Biol Med 21:383-390.

Frei H, Würgler FE, Juon H, Hall CB and Graf U (1985) Aristolochic acid is mutagenic and recombinogenic in Drosophila genotoxicity tests. Arch Toxicol 56:158-166.

Frei H and Würgler FE (1988) Statistical methods to decide whether mutagenicity test data from Drosophila assays indicate a positive, negative, or inconclusive result. Mutat Res 203:297-308.

Frei H and Würgler FE (1995) Optimal experimental design and sample size for the statistical evaluation of data from somatic mutation and recombination tests (SMART) in Drosophila. Mutat Res 334:247-258.

Gentile JM, Rahimi S, Zwiesler J, Gentile GJ and Ferguson LR (1998) Effect of selected antimutagens on the genotoxicity of antitumor agents. Mutat Res 402:289-298.

Gewirtz DA (1999) A critical evaluation of the mechanisms of action proposed for the antitumor effects of the anthracycline antibiotics adriamycin and daunorubicin. Biochem Pharmacol 57:727-741.

Graf U, Würgler FE, Katz AJ, Frei H, Juon H, Hall CB and Kale PG (1984) Somatic mutation and recombination test in Drosophila melanogaster. Environ Mutagen 6:153-188.

Graf U, Frei H, Kägi A, Katz AJ and Würgler FE (1989) Thirty compounds tested in the Drosophila wing spot test. Mutat Res 222:359-373.

Graf U and van Schaik N (1992) Improved high bioactivation cross for the wing somatic mutation and recombination test in Drosophila melanogaster. Mutat Res 271:59-67.

Graf U, Spanó MA, Guzmán Rincón J, Abraham SK and Andrade HH (1996) The wing somatic mutation and recombination test (SMART) in Drosophila melanogaster: An efficient tool for the detection of genotoxic activity of pure compounds or complex mixtures as well as for studies of antigenotoxicity. Afr Newslett on Occup Health and Safety 6(Suppl 1):9-13.

Graf U, Abraham SK, Guzmán-Rincón J and Würgler FE (1998) Antigenotoxicity studies in Drosophila melanogaster. Mutat Res 402:203-209.

Halliwell B (2001) Vitamin C and genomic stability. Mutat Res 475:29-35.

Islaih M, Halstead BW, Kadura IA, Li B, Reid-Hubbard JL, Flick L, Altizer JL, et al. (2005) Relationships between genomic, cell cycle, and mutagenic responses of TK6 cells exposed to DNA damaging chemicals. Mutat Res 578:100-116.

Jensen BV (2006) Cardiotoxic consequences of anthracyclinecontaining therapy in patients with breast cancer. Semin Oncol 33(S8):15-21. 
Kaya B, Creus A, Velázquez A, Yanikoglu A and Marcos R (2002) Genotoxicity is modulated by ascorbic acid: Studies using the wing spot test in Drosophila. Mutat Res 520:93101.

Kastenbaum MA and Bowman KO (1970) Tables for determining the statistical significance of mutation frequencies. Mutat Res 9:527-549.

Konopacka M, Widel M and Rzeszowska-Wolny J (1998) Modifying effect of vitamins $\mathrm{C}, \mathrm{E}$ and beta-carotene against gamma-ray-induced DNA damage in mouse cells. Mutat Res 417:85-94.

Le Bot MA, Riche C, Guedes Y, Kernaleguen D, Simon S, Begue JM and Berthou F (1988) Study of doxorubicin photodegradation in plasma, urine and cell culture medium by HPLC. Biomed Chromatogr 2:242-244.

Lehmann M, Franco A, Vilar KSP, Reguly ML and Andrade HHR (2003) Doxorubicin and two of its analogues are preferential inducers of homologous recombination compared with mutational events in somatic cells of Drosophila melanogaster. Mutat Res 539:167-175.

Minotti G, Menna P, Salvatorelli E, Cairo G and Gianni L (2004) Anthracyclines: Molecular advances and pharmacologic developments in antitumor activity and cardiotoxicity. Pharmacol Rev 56:185-229.

Menegola E, Broccia ML and Renzo FD (2001) Teratogenic effects of doxorubicin in rats at midgestation and at term. Teratog Carcinog Mutagen 21:283-293.

Nefic H (2001) Anticlastogenic effect of vitamin C on cisplatin induced chromosome aberrations in human lymphocyte cultures. Mutat Res 498:89-98.

Odin AP (1997) Vitamins as antimutagens: Advantages and some possible mechanisms of antimutagenic action. Mutat Res 386:39-67.

Prahalathan C, Selvakumar E, Varalakshmi P, Kumarasamy P and Saravanan R (2006) Salubrious effects of lipoic acid against adriamycin-induced clastogenesis and apoptosis in Wistar rat bone marrow cells. Toxicology 222:225-232.

Rao MV, Chinoy NJ, Suthar MB and Rajvanshi MI (2001) Role of ascorbic acid on mercuric chloride-induced genotoxicity in human blood cultures. Toxicol In Vitro 15:649-654.

Resende FA, Barcala CAMA, Faria MCS, Kato FH, Cunha WR and Tavares DC (2006) Antimutagenicity of ursolic acid and oleanolic acid against doxorubicin-induced clastogenesis in Balb/c mice. Life Sci 79:1268-1273.

Rizki M, Amrani S, Creus A, Xamena N and Marcos R (2001) Antigenotoxic properties of selenium: Studies in the wing spot test in Drosophila. Environ Mol Mutagen 37:70-75.

Rizki M, Kossatz E, Creus A and Marcos R (2004) Genotoxicity modulation by cadmium treatment: Studies in the Drosophila wing spot test. Environ Mol Mutagen 43:196203.

Romero-Jiménez M, Campos-Sánchez J, Analla M, Muñoz-Serrano A and Alonso-Moraga A (2005) Genotoxicity and anti-genotoxicity of some traditional medicinal herbs. Mutat Res 585:147-155.

Shamberger RJ (1984) Genetic toxicology of ascorbic acid. Mutat Res 133:135-159.

Siddique YH, Beg T and Afzal M (2005) Antigenotoxic effects of ascorbic acid against megestrol acetate-induced genotoxicity in mice. Hum Exp Toxicol 24:121-127.

Sinigaglia M, Reguly ML and Andrade HHR (2004) Effect of vanillin on toxicant-induced mutation and mitotic recombination in proliferating somatic cells of Drosophila melanogaster. Environ Mol Mutagen 44:394-400.

Spanó MA, Frei H, Würgler FE and Graf U (2001) Recombinagenic activity of four compounds in the standard and high bioactivation crosses of Drosophila melanogaster in the wing spot test. Mutagenesis 16:385-394.

Tripathy NK, Würgler FE and Frei H (1990) Genetic toxicity of six carcinogens and six non-carcinogens in the Drosophila wing spot test. Mutat Res 242:169-180.

Associate Editor: Catarina S. Takahashi 